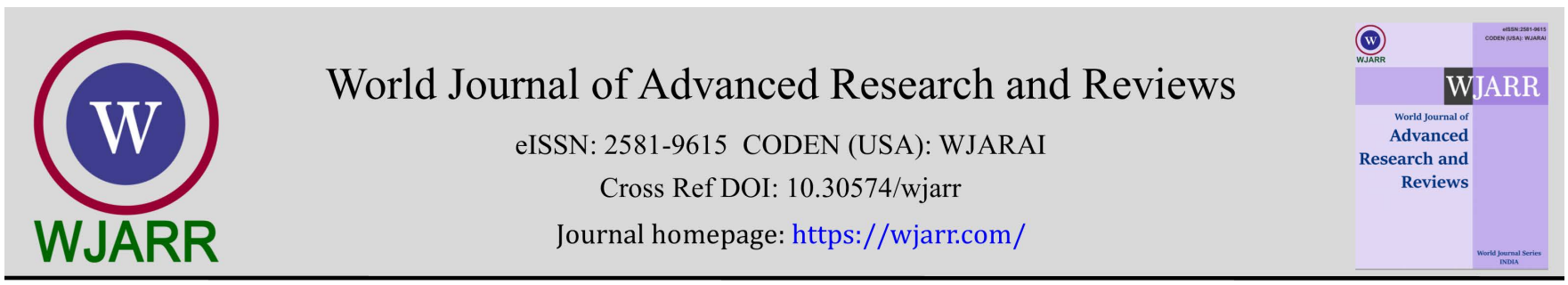

(RESEARCH ARTICLE)

\title{
Formulation and physical characterization of herbal face gel toner
}

\author{
Vibhavari M Chatur *, Sanjay G Walode, Siddhi A Awate, Minal U Gandhi and Vaishnavi S Thorat \\ Rasiklal M Dhariwal Institute of Pharmaceutical Education and Research, Chinchwad, Pune 19, Maharashtra, India.
}

World Journal of Advanced Research and Reviews, 2021, 11(01), 138-145

Publication history: Received on 13 June 2021; revised on 18 July 2021; accepted on 20 July 2021

Article DOI: https://doi.org/10.30574/wjarr.2021.11.1.0333

\begin{abstract}
Topical applications of the drugs have an advantage of delivering the drug directly to the site of action and acting for a longer period of time. Skin is one of the most widespread and readily accessible organs on the human body for topical administration and is the main route of topical drug delivery system. The main aim of this project was to formulate a natural and safe herbal skin toner which has calming, soothing, and astringent, effect on the face and skin to reduce the facial irritancy and enhance the beauty and can be used in day today busy schedule. The extracts used are from the ingredients which are easily available, economical and has nutritional value from topical point of view. Toner has gained the popularity as it can be used daily and helps in restoring the skin texture hence the purpose of the study was aimed for the similar formulation.
\end{abstract}

Keywords: Aloe Vera (Aloe barbadensis miller); Cucumber (Cucumissativus); Honey; Rose Water

\section{Introduction}

\subsection{Herbal Cosmetics}

The herbal cosmetics are the preparations containing phytochemical from a variety of botanical sources, which influences the functions of skin and also provide nutrients necessary for the healthy skin and body [1]. The natural herbs and their products or extract when used for their aromatic value in cosmetic preparation are called as herbal cosmetics [2]. There has been a common belief that the chemical-based cosmetics may be harmful to the skin and turned in increased awareness among consumers for herbal products which triggered the demand for natural products and natural extracts in cosmetics preparations [3].

\subsection{Gel}

A gel is a solid or semisolid system of at least two constituents, consisting of a condensed mass enclosing and interpenetrated by a liquid. The characteristic of gel and jelly is the presence of some form of cutaneous structure, which provides solid-like properties [4] Gels and jellies are composed of small number of solids dispersed in relatively large amount of liquid, yet they possess more solid-like than liquid-like character.

\subsection{Advantages of gel}

- Gels forms can be used to achieve optimal cutaneous and percutaneous drug delivery.

- They are non-invasive and have more patient compliance.

- They can avoid gastrointestinal drug absorption difficulties caused by gastrointestinal pH.

${ }^{*}$ Corresponding author: Vibhavari M Chatur

Institute of Pharmaceutical Education and Research, Chinchwad, Pune 19, Maharashtra, India.

Copyright (C) 2021 Author(s) retain the copyright of this article. This article is published under the terms of the Creative Commons Attribution Liscense 4.0. 
- Gels are having property to avoid enzymatic activity and drug interaction with food, drinks and other products in diet.

- They can avoid the first pass effect, that is, the initial pass of drug substance through the human body.

- They avoid systemic and portal circulation following gastrointestinal absorption.

- Gels are not deactivated by liver enzymes because the liver is bypassed.

- Gels are applied over skin for slow and prolonged absorption.

- They have localized effect with minimum side effects compared to the other forms [5].

\subsection{Toners}

Toner removes any last traces of dirt; grime and impurities stuck in your skin pores after you wash your face. When added to your daily skincare routine and used regularly, it can have major positive impact on the appearance and tightness of your pores (aging skin).[6]

\subsection{Effects of a toner on skin}

Earlier the skin toner was a typical product used as a second cleansing agent for removing residual makeup after regular facial cleansing or used for removing excess sebum secreted from facial skin and to prepare the skin before nourishing treatment. Toners may be categorized into alcohol-based or non-alcohol-based toners for various skin types such as oily skin, sensitive skin, or combination skin. Nowadays, the diversity and prevalence of the products cause skin toners to be utilized more as cosmceutical products with several purposes; for example, rehydrating skin, balancing skin $\mathrm{pH}$, tightening skin pores, relieving irritation, and also antisepsis [6].

\section{Material and methods}

Fresh cucumbers, aloe Vera and roses were obtained from the local market of Pune. Carbopol 934 and methanol were obtained from SD Fine Chemical Ltd. Mumbai. All other chemicals used were of analytical grade.

\subsection{Drug information}

\subsubsection{Cucumber}

Cucumber, Cucumissativus (family- Cucurbitaceous) are obtained throughout India. The silica in cucumber is an essential component of healthy connective tissue, which includes muscles, tendons, ligaments, cartilage, and bone. Cucumber juice is often recommended as a source of silica to improve the complexion and health of the skin, plus cucumber's high-water content makes it naturally hydrating, a must for glowing skin [7].

The flesh of cucumber is primarily composed of water but also contains ascorbic acid (vitamin C) and caffeic acid, both of which help soothe skin irritations and reduce swelling.

\section{Medicinal Importance}

Cucumber has loads of water content to keep skin hydrated. The cooling properties along with antioxidants and silica present in cucumbers help rejuvenate the skin. The flesh of the cucumber is mostly water, but also contains ascorbic acid (vitamin C) and caffeic acid, both of which help soothe skin irritations and reduce swelling and these acids prevent water retention.

\subsubsection{Aloe Vera}

The botanical name of Aloe Vera is Aloe barbadensis miller. It belongs to Asphodelaceae (Liliaceae) family, and is a shrubby or arborescent, perennial, xerophytic, succulent, pea- green color plant [8].

Active components with its properties

Aloe Vera contains 75 potentially active constituents: vitamins, enzymes, minerals, sugars, lignin, saponins, salicylic acids and amino acids [8-11].

\section{Vitamins}

It contains vitamins $\mathrm{A}$ (beta-carotene), $\mathrm{C}$ and $\mathrm{E}$, which are antioxidants. It also contains vitamin B12, folic acid, and choline. 


\section{Enzymes}

It contains 8 enzymes like aliases, alkaline phosphatase, amylase, bradykinase, carboxypeptidase, catalase, cellulase, lipase, and peroxidase. Bradykinase helps to reduce excessive inflammation when applied to the skin topically.

\section{Minerals}

The calcium, chromium, copper, selenium, magnesium, manganese, potassium, sodium and zinc are essential for the proper functioning of various enzyme systems in different metabolic pathways and few are antioxidants.

\subsubsection{Rose water}

Rose water is extracted by distilling rose petals with steam. Rose water is fragrant, and it's sometimes used as a mild natural fragrance as an alternative to chemical-filled perfumes. It's been used traditionally in both beauty products and food and drink products. It also comes with plenty of potential health benefits. It has been used for thousands of years, including in the Middle Ages [13].

Medicinal importance

- Anti-Inflammatory Action

- Moisturizing and Anti-Aging Agent

- Cosmetic \& Skin Protection Application

- Astringent effect on skin pores

- Skin whitening Agent

\subsubsection{Honey}

Honey is a mixture of carbohydrates, proteins, amino acids, vitamins, minerals, antioxidants and other compounds. It consists number of enzymes, including invertase, glucose oxidase, catalase, and acid phosphorylase. Honey also contains eighteen free amino acids, in which the most abundant is proline.

The main group of antioxidants in honey are the Flavonoids, of which, pinocembrin is unique to honey and bee propolis. Naturally darker honey has greater antioxidant properties in it. Acetic, butanoic, formic, citric, succinic, lactic, malic, pyroglutamic, gluconic acids, and a number of aromatic acids are found in honey. Bee's honey is almost free of cholesterols. It also contains trace amounts of the vitamins B2, B4, B5, B6, B11 and vitamin C. Also, Minerals like calcium, iron, zinc, potassium, phosphorous, magnesium, selenium, chromium and manganese are found in honey [14].

\subsection{Preparation of extracts}

\subsubsection{Aloe vera gel}

Steps for Preparation of aloe vera gel:[15]

- $\quad$ The central parenchymatous pulp was scooped out with a spatula from the Aloe leaves and the pulp was washed repeatedly with water and finally treated with $0.1 \mathrm{~N}$ sodium hydroxide $(\mathrm{NaOH})$ to increase the $\mathrm{pH}$ of juice and to avoid to acidity in preparation.

- The treated pulp was placed in a blender to obtain the juice.

- The obtained juice was subjected to vacuum filtration to get clear liquid.

- To the clear liquid so obtained, Carbopol 934 was added and dispersed uniformly ensuring no lumps.

- The prepared aloe vera gel was weighed and stored in air tight containers in a dark room to prevent photooxidation to prepare formulation.

\subsubsection{Cucumber extract}

\section{Preparation of Extract $[16,17]$}

- For isolating the extract from cucumber, cucumbers were properly peeled, washed and chopped finely.

- The chopped material was then crushed in a grinder and the slurry obtained was passed through the muslin cloth in order to obtain the cucumber juice.

- The juice was then lyophilized at a temperature of $-70{ }^{\circ} \mathrm{C}$ so that a freeze-dried extract in the solid form can be obtained.

- $\quad$ The extracts can be stored by keeping in refrigerator till use. 


\subsubsection{Rose water:[18]}

Rose water was extracted through steam distillation method in which rose petals were immediately prepared to go through a very meticulous steam- distillation process. The rose petals are kept in chamber with water.

\subsection{Preparation of gel}

\subsubsection{Preparation of toner gel [17]}

- Required quantity of gelling agent was weighed and dispersed in a small quantity of aloe vera juice to form a homogenous dispersion.

- Required amount of honey and tween 80 weighed and dispersed in above solution.

- Required amount of methanol was then added to the above solution.

- Methyl paraben and propyl paraben were small quantity of water and added to above mixture with continuous stirring.

- $\quad$ The final weight of gel was adjusted with aloe vera gel.

\section{Formulation}

\begin{tabular}{|c|l|c|}
\hline $\begin{array}{c}\text { Sr. } \\
\text { No. }\end{array}$ & \multicolumn{1}{|c|}{ Ingredients } & Amount \\
\hline 1. & Aloe vera Gel & $1 \mathrm{gm}$ \\
\hline 2. & Herbal Extracts & $2.5 \mathrm{ml}$ \\
\hline 3. & Honey & $1 \mathrm{gm}$ \\
\hline 4. & Tween 80 & $1 \mathrm{ml}$ \\
\hline 5. & Methanol & $5 \mathrm{ml}$ \\
\hline 6. & Distilled Water & Upto $25 \mathrm{ml}$ \\
\hline
\end{tabular}

\subsection{Pictures of the formulation}

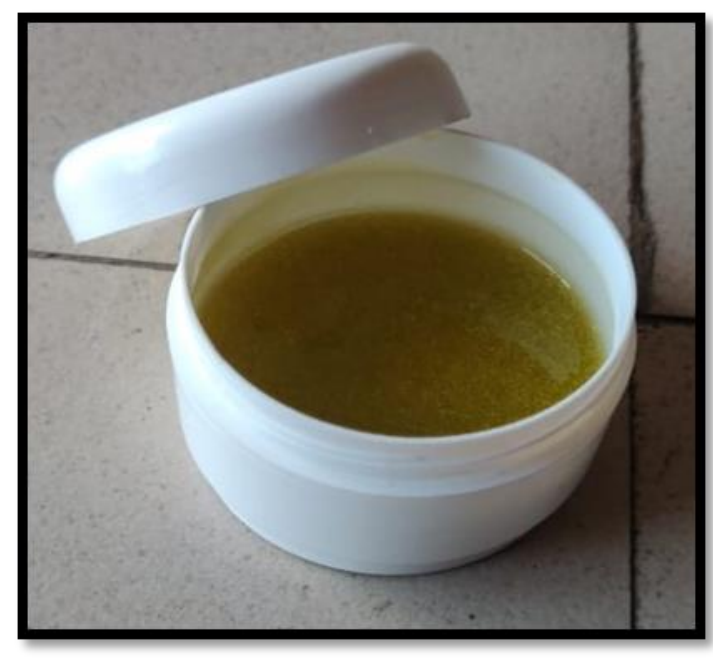

Figure 1 Picture on the day of formulation

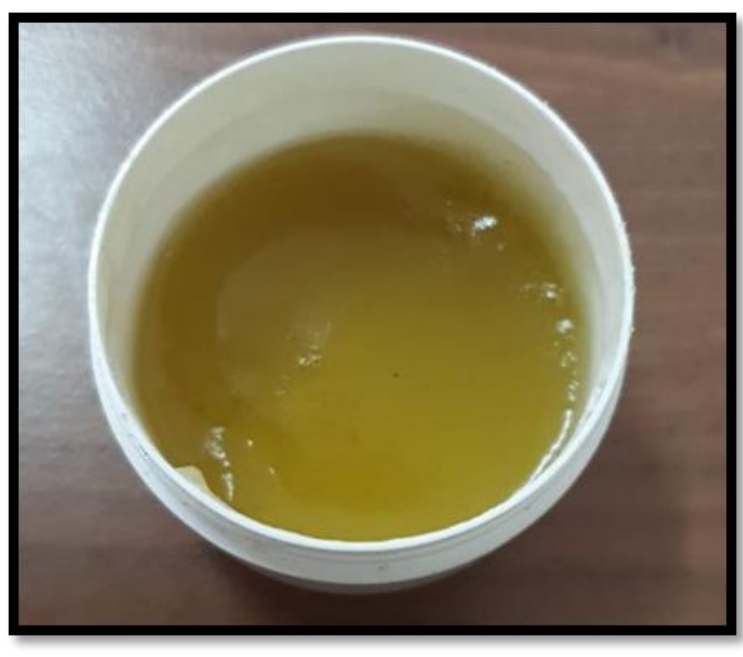

Figure 2 Picture of formulation stability after month

\subsection{Direction for using gel toner}

- Put a few drops of the toner on a cotton pad.

- Apply it all over the face and neck.

- You can also take a few drops in your hands instead of a cotton pad and apply it over your face.

- Allow it to dry. 
- Follow it up with a serum or moisturizer.

\subsection{Evaluation of gel toner}

Preliminary evaluation of formulation was carried out as follows.

\subsection{1. $\mathrm{pH}$}

The pH meter was calibrated and measured the pH by placing in the beaker containing $20 \mathrm{mg}$ of the gel. [19]

\subsubsection{Spreadability Test}

$500 \mathrm{mg}$ of the gel was sandwiched between 2 slides. A weight of $100 \mathrm{gm}$ was placed on upper slide. The weight was removed and extra gel was scrapped off. The lower slide was fixed on board of apparatus and upper slide was fixed with non-flexible string on which $20 \mathrm{~g}$ load was applied. Time taken by upper slide to slip off was noted down and the spread ability was tested.[20]

\subsubsection{Homogeneity}

This test for the gel was done by physical touch with hands.

\subsubsection{Appearance}

The appearance of prepared gel was found by observing its colour, opacity, etc physical parameters.

\subsubsection{After Feel}

After applying the herbal gel toner on skin, the properties like emollient nature, slipperiness and the amount of gel left after application was noted.

\subsubsection{Smear Type}

The test was conducted after the application of gel on the skin the smear formed was oily or aqueous in nature.

\subsubsection{Removal}

The removal of the gel applied on skin was done by washing under tap water with minimal force to remove the gel.

\subsubsection{Patch Test}

About 1-3gm of material to be tested was placed on a piece of fabric or funnel and applied to the sensitive part of the skin e.g., skin behind ears. The cosmetic to be tested was applied to an area of 1sq.m. of the skin. Control patches were also applied. The site of patch is inspected after $24 \mathrm{hrs}$. As there was no reaction the test was repeated three times. As no reaction was observed on third application, the person may be taken as not hypersensitive.[21]

\subsubsection{Irritancy Test}

The gel was applied on left hand dorsal side surface of 1 sq.cm and observed in equal intervals up to $24 \mathrm{hrs}$ for irritancy, redness and oedema. [22]

\subsubsection{Accelerated Stability Studies}

Accelerated stability studies were performed on all the formulations by maintaining at room temperature for 20 days with constant time interval. During the stability studies the parameters like homogeneity, viscosity, physical changes, $\mathrm{pH}$ and type of smear were studied.[23]

\subsubsection{Extrudability}

A simple method was adopted for this study. The formulation was filled in the collapsible tubes after the gel was set in the container. The extrudability of formulation was determined in terms of weight in grams required to extrude a 0.5 $\mathrm{cm}$ of ribbon of gel in 10 second.[24] 


\subsubsection{Diffusion study}

The diffusion study was carried out for the prepared formulation by preparing agar nutrient medium of any concentration. It was poured into petri dish a hole bored at the centre and gel was placed in it. The time taken for the gel to get diffused was noted.[25]

\section{Results}

\subsection{Result of physical characterization}

\begin{tabular}{|c|c|c|}
\hline Sr. No & Parameter & Results \\
\hline 1. & Color & Greenish \\
\hline 2. & Odour & pleasant characteristic \\
\hline 3. & $\mathrm{pH}$ & Non-irritable \\
\hline 4. & Irritability & Cooling \\
\hline 5. & Feel on application & Good \\
\hline 7. & Stability & After two months was stable, has been kept for further study \\
\hline 8. & Consistency & Easily washable \\
\hline 9. & Spreadability & smooth \\
\hline 10. & Washability & consistent \\
\hline 11. & Homogeneity & Bot hypersensitive \\
\hline 12. & By touch & passed \\
\hline 13. & Diffusion Test & Easily extrudable \\
\hline 14. & Extrudability & Easily removable \\
\hline 15. & Removal &
\end{tabular}

\subsection{Toner Results interpretation on hands}

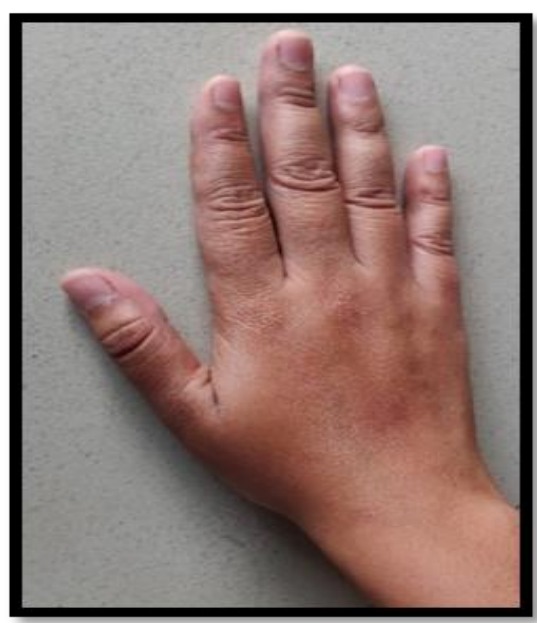

Figure 2a: Before application of gel

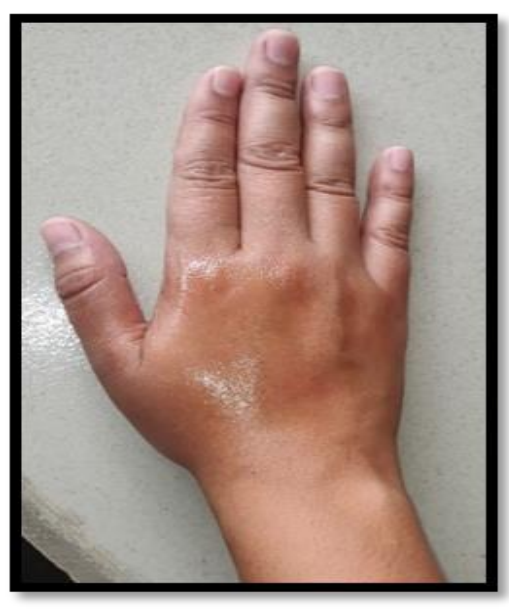

Figure 2b: After application of gel

\section{Results and Discussion}

This herbal formulation especially in a gel form was prepared by using the ingredients which are available in day-today life also, which were very natural and harmless. The main purpose behind formulating it in the form of gel was its easiness in applicability and Spreadability. Also, formulating a toner was intended so as to check the effectiveness of such natural substances like cucumber and aloe vera on the skin and to check whether they are able to produce the 
cleansing effect in a gel form. By seeing the observations and the results, it proved to be satisfactory. The formulation showed on application had very soothing and cleansing and most importantly toning effect on the skin. It gave the feeling of tightened skin.

\subsection{Stability studies}

Accelerated stability studies were performed on the formulation by maintaining at room temperature for 60 days with constant time interval. During the stability studies the parameters like homogeneity, viscosity, physical changes, pH and type of smear were studied and were found to be satisfactory as well.

\section{Conclusion}

From the above studies of the formulation, it is clear that the herbal gel toner prepared is effective for the smoothening, calming, astringent, and rejuvenating effect on the skin. It is non irritable and can be used on daily bases for enhancing the natural beauty of human skin. The formulation was also found to possess significant antioxidant activity which may contribute to its sunscreen activity. In addition to the above-mentioned parameters the gel toner was found to have good homogeneity along with good spreadability and $\mathrm{pH}$ in the range of skin. Thus, the gel form of herbal toner can be used topically for improving the health and rejuvenation of the dried and pale skin. It was also found that the ingredients like cucumber and Aloevera gave the best results for hydration and acne problems.

\section{Compliance with ethical standards}

\section{Acknowledgments}

We thank Mrs. Rohini Kolhe for guiding us and our lab technician and other helpers who made this study possible.

\section{Disclosure of conflict of interest}

The authors declare that there is no conflict of interest.

\section{References}

[1] Larsson SC, Bergkvist L, Näslund I, Rutegård J, Wolk A. Vitamin A, retinol, and carotenoids and the risk of gastric cancer: a prospective cohort study. Am. J. Clin. Nutr. 2007; 85(2): 497-503.

[2] Sweet almond [online], Available from: http://www.cosmetics info. org/ ingredient_details.php?ingredient_id=403

[3] Almond [online], Available from: http://en.wikipedia.org/ wiki/Almond.

[4] Gupta S, Pandit KR. In; Concepts of Pharmaceutical Dosage Form, 9th Edn., B.S. Shah Publication, Delhi. 1997; 155-156.

[5] Tripathi KD. In; Essential of Medical Pharmacology, 5th Edn., Jaypee Brothers Medical Publisher Pvt. Ltd., New Delhi. 2004; 8-16.

[6] Draelos ZD. Astringents, Masks, and Ancillary Skin Care Products. In Textbook of Cosmetic Dermatology, 5thed.; Baran R, Maibach HI, Eds.; CRCPress: Boca Raton, FL, USA. 2017; 178-181.

[7] Rajeev Kumar, Sudhir Arora and Shivani Singh3, Formulation and development of herbal cucumber gel for sunscreen and anti-oxidant activities 5(6): 747-758.

[8] Atherton P. Aloe vera revisited. Br J Phytother. 1998;4:76-83.

[9] Shelton M. Aloe vera, its chemical and therapeutic properties. Int J Dermatol. 1991; 30:679-83.

[10] Atherton P. The essential Aloe vera: The actions and the evidence. 2nd ed. 1997.

[11] Ro JY, Lee B, Kim JY, Chung Y, Chung MH, Lee SK, et al. Inhibitory mechanism of aloe single component (Alprogen) on mediator release in guinea pig lung mast cells activated with specific antigen-antibody reactions.J PharmacolExpTher. 2000; 292:114-21.

[12] Hutter JA, Salmon M, Stavinoha WB, Satsangi N, Williams RF, Streeper RT, et al. Anti-inflammatory C-glucosyl chromone from Aloe barbadensis. J Nat Prod. 1996; 59:541-3. 
[13] Healthline [internet] available fromhttps://www.healthline.com/health/rose-water-benefits

[14] Loveridge J. The chemistry of Bees. 2001. [Last cited on 2010 Feb 12].

[15] Formulation development, optimization and evaluation of aloe vera gel for wound healingAbdul Wadood Khan, SabnaKotta, Shahid Hussain Ansari,1 Rakesh Kumar Sharma,2 Amit Kumar,2 and Javed AliPMCID: PMC3798142PMID: 24143047

[16] Cucumber Free Weekly newsletter. Available http://www.whfoods.com/genpage.php?tname=foodspice\&dbid=42

[17] Mahajan UN, Wasule DD. Sunscreen and Antioxidant Activities of Herbal Gel Formulation. Phcogmag. 2005; 4:99101.

[18] Myung-hee Lee,Tae Gyu Nam, Inil Lee,EunJu Shin, Ah-ram Han, Pomjoo Lee, Sung-Young Lee, Tae-Gyu Lim凶 Skin anti-inflammatory activity of rose petal extract (Rosa gallica) through reduction of MAPK signaling pathway1PMCID: PMC6261181PMID: 30510758

[19] Choochote W, Tueten B, Kanjanapothi D, Rattanachanpichai E, Chaithong U, Chaiwong. Potential of crude seed extract of celery, Apium graveolens, L against the mosquitoes Aedes aegypti. Journal of vector ecology. 2004; 29(2): 340-346.

[20] Sujith S Nair, Molly Mathew, Sreena K. Formulation and Evaluation of Herbal Cream containing Curcuma longa; International Journal of Pharmaceutical And Chemical Sciences. Oct-Dec 2012; 1(4).

[21] A Vijayalakshmi, A Tripura, V Ravichandiran. Development and Evaluation of Anti- Acne Products from Terminaliaarjuna Bark; IJCRGG. 3(1): 320-327.

[22] DebjitBhowmik, Harish Gopinath, B Pragati Kumar, S Duraivel Aravind GKP, Sampath Kumar. Medicinal Uses of Punicagranatumand Its Health Benefits; Journal of Pharmacognosy and Phytochemistry. 2013; 1(5).

[23] Ashish Aswal, MohiniKalra, Abhiram Rout. Preparation and evaluation of polyherbal cosmetic cream; Der Pharmacia Lettre. 2013; 5(1): 83-88.

[24] Vinod KR, Santhosha D, Anbazhagan S. Formulation and Evaluation of PiperineCreama New Herbal Dimensional Approach for Vitiligo Patients; Int J Pharm PharmSci. 2011; 3(2): 293.

[25] Rohan s mestri, harshadapatil, shriyadeshpande, amit p. pratap, formulation of mild natural biodegradable micro beads face scrubber, international journal of engineering research and technology. issn 0974-3154 2017; 10(1). 